\title{
Médiévales
}

Langues, Textes, Histoire

67 | automne 2014

Histoires de Bohême

David RIVAUD, Entrées épiscopales, royales et princières dans les villes du Centre-Ouest de la France (XIV ${ }^{e}$ $\mathrm{XVI} I^{e}$ siècles)

Genève, Droz, 2013, 276 p. (« Travaux d'Humanisme et Renaissance », DVIII)

\section{Cécile Bulté}

\section{(2)enEdition}

Journals

Édition électronique

URL : https://journals.openedition.org/medievales/7346

DOI : 10.4000/medievales.7346

ISSN : 1777-5892

Éditeur

Presses universitaires de Vincennes

\section{Édition imprimée}

Date de publication : 31 décembre 2014

Pagination : 199-201

ISBN : 978-2-84292-422-5

ISSN : 0751-2708

\section{Référence électronique}

Cécile Bulté, "David Rivaud, Entrées épiscopales, royales et princières dans les villes du Centre-Ouest de la France (xIve-xvI ${ }^{e}$ siècles) », Médiévales [En ligne], 67 | automne 2014, mis en ligne le 09 mars 2015, consulté le 22 avril 2022. URL : http://journals.openedition.org/medievales/7346 ; DOI : https:// doi.org/10.4000/medievales.7346

Ce document a été généré automatiquement le 22 avril 2022

Tous droits réservés 


\section{David RIVAUD, Entrées épiscopales, royales et princières dans les villes du Centre-Ouest de la France (XIV ${ }^{e}$ $\mathrm{XVI} I^{e}$ siècles)}

Genève, Droz, 2013, 276 p. (" Travaux d'Humanisme et Renaissance », DVIII)

\section{Cécile Bulté}

\section{RÉFÉRENCE}

David RIVAUD, Entrées épiscopales, royales et princières dans les villes du Centre-Ouest de la France (XIV ${ }^{e}-X V I^{e}$ siècles), Genève, Droz, 2013, 276 p. (« Travaux d'Humanisme et Renaissance », DVIII)

Dans le prolongement de ses travaux menés sur les rituels politiques dans l'espace royal français, David Rivaud publie un nouveau recueil de sources sur les entrées solennelles dans les bonnes villes du Centre-Ouest, longtemps tenues à l'écart des enquêtes historiques. L'ouvrage couvre une trentaine d'accueils épiscopaux (p. 59-102), royaux et princiers (p. 103-181) oude souverains étrangers (p. 104-246), tenus en Poitou, Aunis ou Saintonge, entre le début $d u X^{e}{ }^{e}$ et la fin $d u X V I^{e}$ siècle. Les nombreux documents inédits des Archives nationales, de la Bibliothèque nationale de France ou des fonds municipaux d'Angoulême, La Rochelle, Niort, Poitiers et Saintes, réunis dans cet ouvrage, permettent une appréhension globale de l'événement selon ses acteurs, son financement, ses rituels, ses espaces ou ses décors. Le corpus de textes est précédé de deux articles, le premier de Florence Alazard et Paul-Alexis Mellet intitulé «De la propagande à l'obéissance, du dialogue à la domination : les enjeux de pouvoir dans les entrées solennelles » (p. 9-22), le second de David Rivaud présentant un « Panorama des accueils solennels dans les villes du Centre-Ouest à la fin du Moyen Âge et au début des 
Temps modernes » (p. 23-58). L'ensemble propose une approche comparative originale entre entrées épiscopales, royales et princières, qui donne matière à une réflexion sur les modes de communication politique entre royauté, ville et Église.

L'article de Florence Alazard et Paul-Alexis Mellet introduit l'ouvrage par une synthèse sur trois siècles d'historiographie de l'entrée solennelle en France, depuis les premières transcriptions $d u x \mathrm{XII}^{\mathrm{e}}$ siècle à son inscription, au cours de la seconde moitié du $\mathrm{Xx}^{\mathrm{e}}$ siècle, au sein du champ de recherche sur le "système communicationnel des États » (p. 10). Dans les années 1950-1960, les travaux de Jean Jacquot, Bernard Guenée et Françoise Lehoux ouvrent la voie aux recherches sur l'entrée dans le cadre de la propagande et des méthodes de gouvernement du prince. Ralph. E. Giesey, MarieFrance Wagner ou Daniel Vaillancourt l'abordent par la suite comme rituel ou comme cérémonial d'État, Michèle Fogel ou Vincent Challet comme expression de la toutepuissance de la royauté. L'hypothèse dialogique, plus largement privilégiée depuis les années 1990, diversifie les recherches sur la place et la participation des autorités urbaines aux cérémonies royales ou princières, que Clifford Geertz envisage selon la perspective anthropologique des rituels d'agrégation à une communauté, Christian Jouhaud ou Philippe Hamon comme manifestation de la soumission ou du loyalisme de la ville en échange de la reconnaissance de ses libertés et privilèges. Les auteurs résument ces quarante ans d'historiographie comme le passage "d'une théorie de la souveraineté qui pense le pouvoir à partir d'un lieu - le roi - à une théorie de la domination - qui pense le pouvoir à partir d'un conflit : les différents pouvoirs » (p. 22).

Dans le second article, le panorama des accueils solennels dans les villes du CentreOuest proposé par David Rivaud situe le corpus au cœur d'un espace "profondément intégré aux systèmes monarchiques » français et anglais (p. 23). Par une présentation typologique de la documentation publiée, l'auteur présente l'objet dans la diversité de ses sources (registres de délibération ou de comptes des villes, procès verbaux, lettres royales, annales, mémoires, livrets ou récits imprimés), de ses acteurs (magistrats urbains, officiers royaux parisiens ou provinciaux, universités, corps de métiers, peintres, orfèvres...), et de ses pratiques. Le corpus, vaste et inédit, des entrées d'évêques à Poitiers entre 1307 et 1565 fournit une documentation assez précise pour en dégager certaines spécificités chronologiques, topographiques ou rituelles. Possiblement antérieures à l'entrée royale, elles s'en distinguent notamment, et dès le début $d u$ XIV $^{e}$ siècle, par une plus faible extension dans la ville (les processions ayant souvent lieu à l'intérieur de l'église ou de la cathédrale), certains rituels (prise de possession d'une église ou d'un siège épiscopal, baiser de la croix), une décoration plus discrète, voire absente, enfin l'absence d'intervention des autorités urbaines dans les cérémonies.

4 La participation de la ville au financement, à la conception, à la réalisation et au déroulement des cérémonies est plus spécifique à l'entrée royale ou princière à partir de la fin de la guerre de Cent ans. Selon l'auteur, elle se caractérise alors par « une véritable hypertrophie cérémonielle " (p. 35). À Angoulême, La Rochelle ou Poitiers, celle-ci se traduit sur un plan spatial, par l'extension extra-muros de certains rituels comme la remise des clefs, la présentation officielle des institutions locales ou le franchissement de la muraille qui interrogent la valeur du seuil dans un cadre civil. Elle se manifeste également, sur le plan scénographique, par une «opulence » décorative bien illustrée par l'analyse des comptabilités urbaines et l'exemple des sommes versées à certains artistes, comme l'orfèvre Guyon Brunet, qui reçoit trois cent cinquante livres 
de la ville pour «faire les presens » remis à François I ${ }^{\text {er }}$ lors de son entrée à Poitiers en 1520 (p. 140). Le corpus poitevin fournit également une documentation éclairante sur l'évolution des décors d'échafauds et le passage, au cours des premières décennies du $\mathrm{XVI}^{\mathrm{e}}$ siècle, d'une iconographie chrétienne à de «nouveaux codes antiques » (p.49), qu'illustre bien l'entrée de 1520. Poitiers accueille alors François $\mathrm{I}^{\mathrm{er}}$ au sein d'un décor triomphal de chapeaux, d'arcs et de colonnes au sein desquels des figures mythologiques personnifient les vertus du prince, les nations qui lui rendent hommage et la ville elle-même, représentée par un homme tenant un panonceau où est écrit «Je suis Poictiers » (p. 131). La lecture des sources proposée par David Rivaud souligne ainsi l'action du pouvoir urbain dans la diffusion d'une propagande royale au sein de laquelle l'autorité locale parvient à introduire son image. Cette dimension dialogique trouve sûrement son meilleur exemple dans le cas de la cérémonie "du fil de soie " de La Rochelle, «spécificité rituelle » vernaculaire maintenue sur plus de deux siècles.

La présentation comparative de la documentation réunie dans cet ouvrage permet de penser aux modalités rituelles, spatiales ou iconographiques de communication des institutions et entre les institutions. Le corpus des entrées d'évêques à Poitiers, en particulier, donne matière à une réflexion sur la question de la genèse religieuse de l'entrée royale. Celle-ci est posée par Florence Alazard et Paul-Alexis Mellet, qui rappellent qu'une enquête comparative reste à mener entre la Fête-Dieu, l'entrée royale et l'Entrée du Christ à Jérusalem, dans le cadre d'une réflexion sur l'élaboration «d'une religion royale, signe de l'alliance entre l'Église et la monarchie » (p. 18). Cette observation rejoint la perspective comparative proposée par l'ouvrage, qui donne à voir l'entrée solennelle selon la double perspective de son histoire matérielle et visuelle et comme un objet d'articulation entre les sphères religieuses, royales et urbaines. 